\title{
Onduidelijkheden en complicaties bij de verwerking van eigen aandelen in de jaarrekening
}

\section{Inleiding}

De wet tot aanpassing van de Nederlandse wetgeving aan de tweede EGrichtlijn inzake de kapitaalbescherming van de N.V. is op 1 september 1981 in werking getreden. In deze wet zijn tevens enige wijzigingen in art. 326 van titel 6 BW2 aangebracht. Daar deze titel ook op een B.V. van toepassing is, gelden deze wijzigingen niet alleen voor een N.V., maar ook voor een B.V. Het is niet mijn bedoeling om alle of de voornaamste wijzigingen als gevolg van de aanpassing van de Nederlandse wetgeving aan de tweede EGrichtlijn aan de orde te stellen. Ik moge daarvoor verwijzen naar de bespreking van P.A. Wessel in dit blad ${ }^{1}$. Ik zal slechts een aantal onduidelijkheden en complicaties bij de behandeling van eigen aandelen ${ }^{2}$ in de jaarrekening bespreken. Onderwerpen die aan de orde komen zijn:

- Activeringsverbod eigen aandelen en vrije reserves;

- Eigen aandelen en de waardering van meerderheidsdeelnemingen;

- Eigen aandelen en de geconsolideerde jaarrekening;

- Eigen aandelen en dividend;

- Inlichtingen over eigen aandelen.

\section{Activeringsverbod eigen aandelen en vrije reserves}

De tweede EG-richtlijn staat inkoop van eigen aandelen onder voorwaarden toe. Een uitspraak of activering van eigen aandelen al dan niet is toegestaan wordt in deze - en ook in de vierde - richtlijn niet aangetroffen. Beide mogelijkheden zijn toegestaan. Ingeval eigen aandelen worden geactiveerd dient alsdan ten laste van de vrije reserves een wettelijke reserve te worden gevormd ter grootte van het geactiveerde bedrag. Ingeval eigen aandelen niet mogen worden geactiveerd, dient het bedrag van de eigen aandelen logischerwijze in mindering te komen op de vrije reserves. Alleen dan zijn beide methoden gelijkwaardig.

De Nederlandse wetgever heeft gekozen voor het stelsel waarin het niet toegestaan is om eigen aandelen te activeren. Hierbij heeft de wetgever evenwel bepaald dat het gestorte bedrag op eigen aandelen in mindering moet komen op het gestorte kapitaal en - impliciet - dat het verschil tussen de verkrijgingsprijs en het gestorte bedrag moet worden verwerkt in de vrije 
reserves. Hiermede heeft de Nederlandse wetgever ongelijkwaardigheid ten opzichte van de eerste methode gecreëerd.

Een belangrijk bezwaar van de Nederlandse oplossing is evenwel dat deze oplossing vrije reserves in de balans kan tonen die uit oogpunt van kapitaalbescherming in het geheel niet vrij zijn. Eén van de voorwaarden waaronder inkoop van eigen aandelen mogelijk is c.q. waaronder uitkeringen aan aandeelhouders mogelijk zijn, is dat er voldoende vrije reserves zijn. Vrije reserves zijn gelijk aan het surplus aan eigen vermogen, boven het gestorte en opgevraagde kapitaal, verhoogd met wettelijke en statutaire reserves. Daar inkoop van eigen aandelen de omvang van het gestorte kapitaal niet aantast, zijn de vrije reserves nadat een inkoop heeft plaatsgevonden niet gelijk aan de vrije reserves volgens de balans.

Ter illustratie

Vóór inkoop is de balans $(\times f 1.000)$ :

\begin{tabular}{lr|lr}
\hline Activa & 300 & Gestort kapitaal & 200 \\
& Vrije reserves & $\underline{20}$ \\
& & Passiva & $\underline{80}$ \\
& $\underline{\underline{300}}$ & & $\underline{\underline{300}}$
\end{tabular}

Er vindt inkoop van eigen aandelen plaats. De verkrijgingsprijs is $f 20.000,-$ (nominaal bedrag $f 10.000,-)$. De balans luidt nu $(\times f 1.000)$ :

\begin{tabular}{ll|lr}
\hline \multirow{2}{*}{280} & Gestort kapitaal & 200 \\
& & Eigen aandelen & 10 \\
& & 'Kapitaal' & 190 \\
& & Vrije reserves & $\underline{10}$ \\
& & Eigen vermogen & 200 \\
$\underline{280}$ & Passiva & $\underline{80}$ \\
& & $\underline{\underline{280}}$
\end{tabular}

De vrije reserves zijn volgens de balans $f 10.000$,- . In werkelijkheid zijn de vrije reserves echter nihil. Het eigen vermogen van $f 200.000$,- moet namelijk voor de bepalingen omtrent de toelaatbaarheid van nieuwe inkopen en van uitkeringen aan aandeelhouders vergeleken worden met het gebonden kapitaal dat hier $f 200.000$,- is. Naar het mij voorkomt is hierom de wettelijke oplossing niet juist. De wetgever zal of de voorschriften omtrent inkoop moeten aanpassen ${ }^{3}$, waarvoor m.i. de tweede EG-richtlijn geen ruimte biedt of moeten bepalen dat de verkrijgingsprijs van ingekochte eigen aandelen in mindering moet komen op de vrije reserves.

De vraag blijft wat men thans in voorkomende gevallen moet doen. De aftrek op het gestorte kapitaal in de balans of toelichting is uitdrukkelijk voorgeschreven. Men kan echter ook geen hogere vrije reserves tonen dan er zijn. Het overboeken van de $f 10.000,-$ vrije reserves naar een wettelijke 
reserve gaat ook niet omdat alsdan het gebonden kapitaal $f 210.000$,wordt, bij een eigen vermogen van $f 200.000,-$. Het enige wat blijft is een uiteenzetting in de toelichting dat een bedrag van $f 10.000,-$ niet uitkeerbaar is. Wetswijziging is op dit punt stellig noodzakelijk. De gesignaleerde complicatie kan worden voorkomen door de betrokken aandelen tijdig in te trekken.

Volledigheidshalve merk ik op dat het gesignaleerde vraagstuk evenzeer optreedt bij verkrijgingen van eigen aandelen tegen pariwaarde, en beneden pariwaarde (waaronder verkrijgingen om niet), alsmede bij verkrijgingen van eigen aandelen onder algemene titel. In het laatste geval kan er nog een onduidelijkheid ontstaan. Uitdrukkelijk wordt voorgeschreven dat het nominaal gestorte bedrag op gehouden eigen aandelen in mindering komt op het gestorte kapitaal. Hoe moet nu gehandeld worden indien niet volgestorte aandelen worden verkregen? Moet nu de nominale waarde of het gestorte bedrag in mindering worden gebracht? Een redelijke uitleg is m.i. de laatste zienswijze. Terzijde zij evenwel opgemerkt dat in het wetsontwerp aanpassing vierde EG-richtlijn voor de eerste zienswijze is gekozen.

\section{Eigen aandelen en de wardering van meerderheidsdeelnemingen}

Eigen aandelen kunnen eveneens via meerderheidsdeelnemingen worden gehouden. De verkrijging daarvan is mogelijk indien de N.V. zelve de aandelen had mogen verkrijgen. Een vraagstuk dat nu naar voren komt is of de waardering van meerderheidsdeelnemingen in de balans van de rechtspersoon (N.V. of B.V.) beïnvloed wordt door de omstandigheid dat de meerderheidsdeelnemingen aandelen in het kapitaal van de rechtspersoon houden.

In de Memorie van Antwoord bij de toen nog in ontwerp zijnde wet verwijst de Minister voor een nadere regeling naar het wetsontwerp aanpassing vierde EG-richtlijn. Ik meen dat deze verwijzing ten onrechte geschiedde, daar de gesignaleerde problematiek reeds thans actueel is. Indien wordt aangenomen dat het gebruikelijk is om meerderheidsdeelnemingen in de geconsolideerde jaarrekening op te nemen en dat het wenselijk wordt geoordeeld eenzelfde eigen vermogen volgens de enkelvoudige balans en volgens de geconsolideerde balans te verantwoorden, kan de conclusie niet anders zijn dan dat de waardering van betrokken meerderheidsdeelnemingen moet worden aangepast. Niet vergeten mag worden dat de bepalingen van titel $6 \mathrm{BW} 2$ (waaronder dus het activeringsverbod van eigen aandelen) ook van toepassing zijn op de geconsolideerde jaarrekening. Het behoort geen verschil uit te maken of de rechtspersoon eigen aandelen rechtstreeks dan wel via meerderheidsdeelnemingen ${ }^{4}$ houdt. 


\section{Ter illustratie}

De balans van de moederrechtspersoon geeft aan $(\times f 1.000)$ :

\begin{tabular}{ll|lr}
\multicolumn{4}{c}{ A } \\
\hline Aandelen in B (100\%) & 160 & Gestort kapitaal & 200 \\
Overige activa & 140 & Vrije reserves & $\underline{20}$ \\
& & Eigen vermogen & 220 \\
& $\underline{\underline{300}}$ & Passiva & $\underline{80}$ \\
& & $\underline{\underline{300}}$
\end{tabular}

De balans van de meerderheidsdeelneming geeft aan $(\times f 1.000)$ :

$\mathrm{B}$

Aandelen in A $(8 \%)$

20

Gestort kapitaal

100

Overige activa

Vrije reserves

Eigen vermogen

Passiva

Aangenomen is dat B de aandelen A tegen verkrijgingsprijs van $f 20.000,-$ heeft geactiveerd. Waardering tegen intrinsieke waarde is niet zinvol. Indien aangenomen zou zijn dat $\mathrm{A}$ zelf de eigen aandelen had verkregen dan is de balans van $\mathrm{A}$ als volgt $(\times f 1.000)$ :

\begin{tabular}{ll|lr}
\hline Aandelen in B & 160 & Gestort kapitaal & 200 \\
Overige activa & 120 & Eigen aandelen & $\underline{16}$ \\
& & 'Kapitaal' & 184 \\
& Vrije reserves & $\underline{16}$ \\
& Eigen vermogen & 200 \\
& $\underline{\underline{280}}$ & Passiva & $\underline{\underline{8280}}$ \\
\hline
\end{tabular}

Het ligt daarom voor de hand, nu inkoop via $B$ heeft plaatsgevonden de waardering van $B$ aan te passen, onder gelijktijdige correctie van het eigen vermogen van $A$. De juiste balans van $A$ wordt dan $(\times f 1.000)$ :

\begin{tabular}{ll|lr}
\hline Aandelen in B & 140 & Gestort kapitaal & 200 \\
Overige activa & 140 & Eigen aandelen & $\underline{16}$ \\
& & 'Kapitaal' & 184 \\
& & Vrije reserves & $\underline{16}$ \\
& Eigen vermogen & 200 \\
& $\underline{\underline{280}}$ & Passiva & $\underline{80}$ \\
& & $\underline{\underline{280}}$
\end{tabular}

Overigens wijs ik op mijn eerdere opmerkingen over het 'vrije' karakter van de vrije reserves (de omvang is in werkelijkheid nihil). 


\section{Eigen aandelen en geconsolideerde jaarrekening}

In het verlengde van hetgeen ik in de vorige paragraaf opmerkte kunnen via meerderheidsdeelnemingen gehouden eigen aandelen in de geconsolideerde balans niet als actiefpost voorkomen. Men zal dus eerst de (enkelvoudige) balans van de moederrechtspersoon moeten corrigeren, alvorens te consolideren met de balans van de dochtervennootschap. Dit betekent voor het zojuist besproken voorbeeld dat de geconsolideerde balans er als volgt uitziet $(\times f 1.000)$ :

\begin{tabular}{ll|lr}
\hline \multirow{3}{*}{ Activa } & Gestort kapitaal & 200 \\
& Eigen aandelen & $\underline{16}$ \\
& & 'Kapitaal' & 184 \\
& Vrije reserves & $\underline{16}$ \\
& Eigen vermogen & 200 \\
$\underline{\underline{380}}$ & Passiva & $\underline{\underline{180}}$ \\
& & $\underline{\underline{380}}$
\end{tabular}

Ook hier blijft gelden dat de vrije reserves in werkelijkheid nihil zijn.

Een vraagstuk dat evenwel de aandacht vraagt is het volgende. Het corrigeren van de waardering van meerderheidsdeelnemingen loopt goed zolang het om een $100 \%$-deelneming gaat. Zodra het om een niet $100 \%$-deelneming gaat, die wel geconsolideerd wordt, ontstaat de vraag of in de (enkelvoudige) balans de waardering van de meerderheidsdeelneming moet worden aangepast overeenkomstig het deelnemingspercentage dan wel voor $100 \%$.

De eerste oplossing is gekozen in het wetsontwerp aanpassing vierde EGrichtlijn.

Ter illustratie

De balans van $\mathrm{A}$ is als volgt $(\times f 1.000)$ :

\begin{tabular}{lr|lr}
\multicolumn{4}{c}{ A } \\
\hline Aandelen in B $(60 \%)$ & 96 & Gestort kapitaal & 200 \\
Overige activa & 204 & Vrije reserves & $\underline{20}$ \\
& & Eigen vermogen & 220 \\
& $\underline{\underline{300}}$ & Passiva & $\underline{80}$ \\
& & $\underline{\underline{300}}$
\end{tabular}

De balans van deelneming B geeft aan $(\times f 1.000)$ :

\begin{tabular}{lr|lr}
\multicolumn{3}{c}{ B } \\
\hline Aandelen in A (8\%) & 20 & Gestort kapitaal & 100 \\
Overige activa & 240 & Vrije reserves & $\underline{60}$ \\
& & Eigen vermogen & 160 \\
& $\underline{\underline{260}}$ & Passiva & $\underline{\underline{100}}$ \\
& & $\underline{\underline{260}}$
\end{tabular}


Volgens het wetsontwerp aanpassing vierde EG-richtlijn dient $60 \%$ van $f 20.000$, - in mindering te worden gebracht op de waardering van deelneming $B$ en op het eigen vermogen. De aangepaste balans van $A$ is derhalve $(\times f 1.000)$ :

\begin{tabular}{lr|lr}
\hline Aandelen in B & 84 & Gestort kapitaal & 200,0 \\
Overige activa & 204 & Eigen aandelen & $\underline{9.6}$ \\
& & 'Kapitaal' & 190,4 \\
& Vrije reserves & $\underline{17.6}$ \\
& Eigen vermogen & 208,0 \\
& $\underline{\underline{288}}$ & & $\underline{\underline{80,0}}$ \\
& & $\underline{\underline{288,0}}$
\end{tabular}

De geconsolideerde balans van $\mathrm{A}$ is dan als volgt $(\times f 1.000)$ :

\begin{tabular}{lr|lr}
\hline Aandelen in B & 8 & Gestort kapitaal & 200,0 \\
Overige activa & 444 & Eigen aandelen & $\underline{9.6}$ \\
& 'Kapitaal' & 190,4 \\
& Vrije reserves & $\underline{17,6}$ \\
& Eigen vermogen & 208,0 \\
& Minderheidsbelangen & 64,0 \\
& $\underline{\underline{452}}$ & & $\underline{\underline{180,0}}$ \\
& & $\underline{\underline{452,0}}$
\end{tabular}

Hieruit blijkt dat thans eigen aandelen, overeenkomstig het deelnemingspercentage van minderheidsbelangen in B $(40 \% \times f 20.000,-)$ geactiveerd blijven op de geconsolideerde balans van $A$. Dit verdraagt zich moeilijk met het activeringsverbod van eigen aandelen. Een oplossing zou zijn om de $f 8.000$, - (zichtbaar) in mindering te brengen op de post minderheidsbelangen. Deze oplossing bevredigt niet helemaal omdat deze post eigen aandelen voor minderheidsbelangen een echt activum vormt. Voor zover consolidatie zuiver en alleen op financiële criteria geschiedt, is dit m.i. evenwel de meest doelmatige oplossing.

Ingeval consolidatie geschiedt omdat in B meerderheidszeggenschap bestaat en derhalve A door haar meerderheidspositie de inkoop heeft doen plaatsvinden, is een oplossing als zojuist aangegeven onjuist. In die situatie past veeleer om de waardering van aandelen $B$ met $100 \%$ van de verkrijgingsprijs van de aandelen $A$ te corrigeren. De aangepaste balans van $A$ is alsdan $(\times f 1.000)$ :

Aandelen in B

Overige activa

76
204

Gestort kapitaal

Eigen aandelen

'Kapitaal' 184

Vrije reserves

Eigen vermogen

Passiva 
De geconsolideerde balans van A laat zien $(\times f 1.000)$ :

\begin{tabular}{|c|c|c|c|}
\hline \multirow[t]{4}{*}{ Activa } & 444 & $\begin{array}{l}\text { Gestort kapitaal } \\
\text { Eigen aandelen }\end{array}$ & $\begin{array}{r}200 \\
16 \\
\end{array}$ \\
\hline & & $\begin{array}{l}\text { 'Kapitaal' } \\
\text { Vrije reserves }\end{array}$ & $\begin{array}{r}184 \\
16 \\
\end{array}$ \\
\hline & & $\begin{array}{l}\text { Eigen vermogen } \\
\text { Minderheidsbelangen } \\
\text { Passiva }\end{array}$ & $\begin{array}{r}200 \\
64 \\
180 \\
\end{array}$ \\
\hline & 444 & & 444 \\
\hline
\end{tabular}

Het is gewenst dat de Nederlandse wetgever over de juiste gedragslijn helderheid verschaft. Mijn voorkeur gaat uit naar de laatste gedragslijn, mits het steeds om groepsvennootschappen (w.o. deelnemingen met meerderheidszeggenschap) gaat. Zolang echter het zijn van meerderheidsdeelnemingen primair wordt afgemeten aan financiële criteria, ligt onder de geldende wet de eerste gedragslijn meer voor de hand.

\section{Eigen aandelen en dividend}

Onder de tot 1 september 1981 geldende wet telden voor de berekening van de dividenduitkeringen ook de door de rechtspersoon gehouden eigen aandelen mede, behoudens statutair afwijkende regeling. Dit was ook niet onlogisch, mede omdat eigen aandelen mochten worden geactiveerd. $\mathrm{Nu}$ er echter een activeringsverbod voor gehouden eigen aandelen is, ligt een bepaling als zojuist genoemd niet voor de hand. Een voorschrift dat aangeeft dat eigen aandelen voor de berekening van het dividend niet meetellen, behoudens statutair afwijkende regeling zou men verwachten. Deze verwachting komt evenwel niet uit. Het oude voorschrift is behouden gebleven.

Een vraagstuk dat nu naar voren komt is, hoe dividend op eigen aandelen in de jaarrekening moet worden verwerkt, indien zij statutair voor de dividendberekening niet zijn uitgesloten. Gesteld dat de balans vóór winstbestemming is opgesteld dan is er niets aan de hand. Gebruikelijk is evenwel dat het voorstel tot winstbestemming in de balans wordt verwerkt. Het bedrag, aan te wenden voor dividend verschijnt alsdan als schuld. Dit betekent voor dividend op eigen aandelen in feite een schuld aan de N.V. zelve. Op het moment dat de winstbestemming definitief wordt vastgesteld, is deze schuld een feit. Terzelfdetijd ontstaat een vordering op de N.V. zelf, welke door schuldvermenging teniet gaat. De vraag is wel waarop de tegenboeking van de ontstane vordering moet geschieden. Strikt genomen is de enige mogelijkheid een dergelijk dividend als dividend op eigen aandelen in de winst- en verliesrekening van het jaar van betaalbaarstelling van het dividend te boeken.

Nauw hangt met het bovenstaande samen de dividendverantwoording op via meerderheidsdeelnemingen gehouden eigen aandelen. $\mathrm{Zij}$ zullen ongetwijfeld de betreffende dividenden verantwoorden via hun winst- en ver- 
liesrekeningen in het jaar van betaalbaarstelling. Uit dien hoofde gaat de waardering van de betrokken meerderheidsdeelnemingen omhoog en wordt derhalve de dividendpost als bate in de (enkelvoudige) winst- en verliesrekening verwerkt. In de geconsolideerde winst- en verliesrekening verschijnt dit bedrag eveneens.

Men zou overigens kunnen stellen dat het in verband met het activeringsverbod van eigen aandelen niet past om dividenden op eigen aandelen in het jaar van betaalbaarstelling als bate te nemen. Verdedigbaar lijkt om deze post rechtstreeks aan de vrije reserves, mits duidelijk toegelicht, toe te voegen. In het geval meerderheidsdeelnemingen aandelen in het kapitaal van de rechtspersoon houden, zal de waardering van deze meerderheidsdeelnemingen, met het dividendaandeel op die aandelen moeten worden verhoogd met als tegenpost de vrije reserves. Alsdan zal deze post ook niet in de geconsolideerde winst- en verliesrekening voorkomen.

\section{Inlichtingen over eigen aandelen}

Er moeten door een N.V. en een B.V. inlichtingen worden verstrekt over op balansdatum gehouden eigen aandelen (aantal, soort, nominaal bedrag en het gedeelte dat zij van het geplaatste kapitaal uitmaken $)^{5}$. Bovendien moet een N.V. die genoemde inlichtingen (m.u.v. het vierde gegeven) ook verstrekken over via meerderheidsdeelnemingen gehouden eigen aandelen (art. 98d lid 8 BW2) ${ }^{6}$. Daar op de geconsolideerde jaarrekening ook titel 6 BW2 van toepassing is zullen N.V.'s en B.V.'s de bedoelde vier inlichtingen over de eigen aandelen steeds voor de geconsolideerde eenheid moeten verstrekken.

Voorts moeten N.V.'s ${ }^{8}$ en B.V.'s inlichtingen over transacties in eigen aandelen vermelden (per transactie: aantal, nominaal bedrag, de prijs en het gedeelte dat zij van het geplaatste kapitaal uitmaken en voorts bij verwerving: de redenen) ${ }^{9}$. Gegevens over deze transacties, welke via meerderheidsdeelnemingen zijn gelopen behoeven niet te worden vermeld, omdat dit zou kunnen leiden - aldus de Minister - tot een nauwelijks overzichtelijke menigte gegevens, waarvan de waarde slechts betrekkelijk zou zijn. Ook hier geldt evenwel dat titel 6 BW2 ook van toepassing is op de geconsolideerde jaarrekening zodat m.i. de gegevens over transacties in eigen aandelen (van de N.V. of B.V.) voor de gehele geconsolideerde eenheid moeten worden vermeld.

Overigens kan men zich wel afvragen op welke wijze de bovenliggende rechtspersoon inlichtingen over via meerderheidsdeelnemingen gehouden of verhandelde eigen aandelen te weten kan komen. De betrokken meerderheidsdeelnemingen behoeven deze inlichtingen niet in hun jaarrekeningen op te nemen, terwijl ook een rechtstreekse informatieplicht daartoe ontbreekt. De wetgeving zou op dit punt moeten worden gewijzigd, waarbij het zinvol is een dergelijke informatieplicht te leggen op groepsondernemingen (waaronder in ieder geval deelnemingen waarin meerderheidszeggenschap kan worden uitgeoefend). Deze constatering is evenzeer van belang voor hetgeen ik onder de paragrafen 3-5 opmerkte. 


\section{Afsluitende opmerkingen}

In het voorgaande heb ik een aantal kanttekeningen geplaatst bij het gewijzigde art. 326 en enige daarmee samenhangende wetsbepalingen zonder naar volledigheid te streven. Hopelijk zullen de gesignaleerde onduidelijkheden resp. complicaties ter gelegenheid van de aanpassing van de wetgeving aan de vierde EG-richtlijn worden weggenomen resp. opgelost. Ter afsluiting wil ik nog op een mogelijke complicatie in de toekomst wijzen. In de huidige wet wordt het deelnemingsbegrip gekoppeld aan een zeker percentage van het geplaatste kapitaal. Het ontwerp aanpassingswet vierde EG-richtlijn spreekt over 'kapitaal'. Indien ik afga op het rapport van de Commissie Vennootschapsrecht over 'Rechtspersonen die volledig aansprakelijk vennoot zijn'10 zou gelet moeten worden op het gestorte kapitaal na aftrek van gehouden eigen aandelen. Aan de hand van dit saldo wordt bepaald of aan de deelnemingsgrenzen wordt voldaan, hetgeen derhalve een wezenlijke wijziging ten opzichte van het geldend recht betekent. ${ }^{11}$ Bovendien zullen de reeds besproken complicaties terzake van via meerderheidsdeelnemingen gehouden eigen aandelen ook op de omvang van deelnemingspercentages van invloed zijn.

\section{Noten}

IP. A. Wessel, De komende wettelijke voorschriften voor de kapitaalbescherming van naamloze vennootschappen in hun relatie tot de financiële verslaggeving, MAB, oktober 1980 en november 1980.

2 Tenzij anders vermeld worden onder eigen aandelen steeds begrepen certificaten van deze aandelen.

3 Bijuoorbeeld, zoals bepleit door P. A. Wessel, MAB, 1980, p. 437.

4 Strikt genomen zou het eigenlijk moeten gaan om groepsondernemingen c.q. om deelnemingen warin meerderheidszeggenschap kan worden uitgeoefend.

5 Dit geldt ook voor in pand gehouden eigen aandelen, met een uitzondering voor kredietinstellingen.

6 Het in pandnemen door meerderheidsdeelnemingen is niet toegestaan, met een uitzondering voor kredietinstellingen.

7 Niet naleving van dit voorschrift kan niet voor de Ondernemingskamer worden gebracht.

8 Tenzij beleggingsmaatschappij met veranderlijk kapitaal.

9 Buiten aanmerking blijven rechtshandelingen van vo6r 1 september 1981.

10 Rapport d.d. 27 augustus 1981.

11 Uit de in maart 1982 ingediende Nota van wijzigingen op het wetsontwerp aanpassing vierde EG-richtlijn blijkt dat deze complicatie is opgeheven. Verduidelijkt is dat het gaat om het geplaatste kapitaal, na aftrek van gehouden eigen aandelen. 